Paidéia, 2004, 14 (28), 153 -167

\title{
ALCANCES E LIMITES DO PSICODIAGNÓSTICO INTERVENTIVO NO TRATAMENTO DE CRIANÇAS ANTI-SOCIAIS ${ }^{1}$
}

\author{
Valéria Barbieri ${ }^{2}$ \\ André Jacquemin \\ Zélia Maria Mendes Biasoli Alves \\ FFCLRP - Universidade de São Paulo
}

\begin{abstract}
Resumo: Embora o Psicodiagnóstico Interventivo venha se revelando uma prática promissora, há poucas investigações sistemáticas sobre seus alcances e limitações. Nesse sentido esta pesquisa averiguou, em oito crianças, se o sucesso ou fracasso nesse método vincular-se-ia à estrutura de personalidade e condições das funções egóicas. Para tanto, os sujeitos submeteram-se à aplicação clássica da Técnica de Rorschach, sendo posteriormente encaminhados ao Psicodiagnóstico Interventivo, realizado mediante sessões lúdicas, entrevista familiar, Bateria Hammer e CAT- A. O folow-up dos casos indicou, em relação à melhora dos sintomas, cinco sucessos, dois fracassos e uma desistência. A Técnica de Rorschach mostrou que as crianças bem sucedidas apresentavam estrutura de personalidade neurótica e ausência de comprometimentos severos no Controle Pulsional e nos Relacionamentos Pessoais. Portanto, esses poderiam ser critérios de indicação para esse tratamento, embora as contra-indicações não sejam claras, dados os bons resultados alcançados por Winnicott com crianças psicóticas no procedimento similar de Consulta Terapêutica.
\end{abstract}

Palavras-chave: psicodiagnóstico interventivo; transtorno de conduta; técnica de Rorschach; prognóstico terapêutico.

\section{REACHES AND LIMITATIONS OF THE INTERVENTIVE PSYCHODIAGNOSIS IN THE TREATMENT OF ANTI-SOCIAL CHILDREN}

\begin{abstract}
Although the Interventive Psychodiagnosis has been revealing itself as a promising practice, there are few systematic studies about its reaches and limitations. In this sense, this research investigated, in eight children, if the success or failure in this method could be linked to the personality structure and the conditions of the functions of the ego. For that, the subjects were submitted to a classical application of the Rorschach Technique and after that, they were guided to the Interventive Psychodiagnosis, which was accomplished through ludic sessions, family interview, Hammer Battery and CAT-A. The cases' follow up indicated, regarding to the symptoms amelioration, five success, two failures and one discontinuation. The Rorschach Technique showed out that the well succeeded children presented neurotic personality structure, and lack of severe handicaps in the Control of the Pulsions and in the Personal Relationships. Therefore, these could be criteria for indicating this treatment, although the contraindications are not clear, due to the good results reached by Winnicott with psychotic children in the similar procedure of Therapeutic Consultation.
\end{abstract}

Key-words: interventive psychodiagnosis; conduct isorder; Rorschach technique; therapeutic prognosis.

Psicodiagnóstico Interventivo consiste em uma prática da Psicologia Clínica que integra simultaneamente os processos avaliativo e terapêutico.

\footnotetext{
${ }^{1}$ Artigo recebido para publicação em 13/10.2003; aceito em 08/12/2003. ${ }^{2}$ Endereço para correspondência: Valéria Barbieri, Departamento de Psicologia e Educação, Faculdade de Filosofia, Ciências e Letras de Ribeirão Preto, USP, Av. Bandeirantes, 3900, Monte Alegre, Ribeirão Preto, SP, 14040-901, E-mail valeriab@ffclrp.usp.br
}

Nesse método de intervenção são utilizados assinalamentos e interpretações desde a primeira entrevista com o paciente e durante a aplicação de técnicas projetivas. Sua fundamentação repousa no potencial da situação diagnóstica para trazer à tona, de maneira concentrada, aspectos centrais da personalidade do indivíduo (Cunha \& Cols., 2000; Ocampo, 


\section{Valéria Barbieri}

Arzeno \& Piccolo, 1979/1987; Trinca, 1997), essenciais para a compreensão de seus conflitos e tensões, de sua gênese e das experiências necessárias para a retomada da saúde ou, nas palavras de Aberastury (1979/1986), as fantasias de doença e de cura. A emersão dessa quantidade de material ocorre porque, principalmente durante aplicação das técnicas projetivas, o examinando é convidado a se defrontar, em um tempo restrito, com etapas variadas do seu desenvolvimento pessoal (e com os conflitos a elas associados), seja revivendo cada uma delas, ou expressando uma visão global de si que traz implícitos, mas reconhecíveis, os resultados dessa evolução afetiva (Barbieri, 2002). Em acordo com essas concepções, Winnicott (1948/1993) afirma que é possível realizar um pequeno tratamento psicanalítico já nas entrevistas iniciais, pois nelas surgem elementos que levariam meses ou anos para emergir novamente em uma psicoterapia, observação que o conduziu ao delineamento das Consultas Terapêuticas (Winnicott, 1971/1984).

A despeito de sua semelhança com as Consultas Terapêuticas, o Psicodiagnóstico Interventivo dispõe das vantagens proporcionadas pelo uso dos testes psicológicos, como a maior segurança diagnóstica, a possibilidade de verificar com precisão a natureza e profundidade das mudanças que ele acarreta na personalidade (através de reteste no follow-up), e a chance de investigar, de maneira objetiva, quais pacientes poderiam se beneficiar com a sua aplicação e as contra-indicações.

Apesar de estar sendo sistematizada apenas nos últimos anos, a idéia de realizar intervenções durante a aplicação de técnicas projetivas não é nova. Já no artigo de lançamento do TAT, Morgan e Murray (1935) propuseram o emprego desse teste no tratamento de pessoas levemente comprometidas, questão que foi posteriormente aprofundada por Bellak (1974), embora com variações no procedimento original. Friedenthal (1976) também sugeriu o uso do TRO de Phillipson acrescido de perguntas, pedidos de esclarecimentos e de associações, bem como de assinalamentos e interpretações, visando explorar a capacidade de insight do paciente, ou converter a aplicação do teste em uma ação terapêutica. Inspiradas em Friedenthal, Ancona-Lopez e Cols. (1995) propuseram o método do Psicodiagnóstico Grupal
Interventivo, dirigido a crianças, e que inclui a utilização de sessões lúdicas e aplicações coletivas de testes, sempre acompanhadas por intervenções do examinador. Mais recentemente, Gomes e Bronstein (2000) ilustraram a aplicação de um Psicodiagnóstico Interventivo em uma menina obesa de 3 anos de idade, mas não incluíram testes psicológicos em seu método, restringindo-se ao uso de entrevistas e sessões lúdicas.

Em estudo anterior estabelece-se os fundamentos teóricos do Psicodiagnóstico Interventivo, conforme foi concebido, e ilustrou-se sua utilização em uma criança de 10 anos de idade com comportamentos de furto (Barbieri, 2002). Uma compreensão mais profunda sobre os processos envolvidos nessa situação que engendram efeitos terapêuticos, e sobre a importância da participação da família no procedimento clínico pode ser obtida nesse trabalho.

Embora a literatura seja unânime em afirmar o caráter promissor dessa prática clínica (Bellak, 1974; Friedenthal, 1976; Ancona-Lopez \& Cols., 1995; Gomes \& Bronstein, 2000), as verificações a respeito do seu alcance terapêutico, especificamente para quais pacientes ele seria indicado ou não, ainda são esparsas e informais.

Ancona-Lopez e Cols. (1995), enfatizam que a eficácia do Psicodiagnóstico Interventivo da criança depende das características do ambiente familiar. Nesse sentido, se houver flexibilidade e condições de modificação por parte dos pais, o método pode ser suficiente, sem a necessidade de psicoterapia posterior. Assim, simultaneamente ao atendimento da criança, realizam o grupo de pais para averiguar suas condições de auxiliar o filho, e proporcionar-lhes uma nova percepção dele, no intuito de engendrar formas alternativas de relacionamento. Do mesmo modo Winnicott (1971/1984), em relação às Consultas Terapêuticas, afirma ser possível obter um bom resultado mesmo com crianças seriamente doentes, mas reitera que, se ela retornar para um ambiente familiar e social anormal, não haverá provisão alguma da experiência que ela necessita, e o trabalho tenderia a fracassar.

A importância do meio familiar nos resultados do método não deve, contudo, ofuscar a consideração das características das crianças em tratamento. Shields (1999), criticando a Psicologia do Self, asse- 
vera que a ênfase excessiva que essa abordagem confere ao papel do espelhamento e ao vínculo com as pessoas reais no fortalecimento da personalidade, traz como corolário a desvalorização da necessidade do indivíduo de buscar, de modo responsável e diligente, a experiência que lhe falta. Por outro lado, a teoria winnicottiana, a despeito de valorizar muito o ambiente emocional durante a maturação, também sublinha o desenvolvimento vital que ocorre quando o âmago do verdadeiro self encontra o caminho para ser ativo em seu próprio benefício. De acordo com Shields (1999), mesmo quando a expressão do self está comprometida por processos patológicos, a pessoa sempre se empenha na busca pela cura, ou seja, o valor do potencial vital jamais é deixado de lado, independente das circunstâncias.

Aplicando esse pressuposto à definição do prognóstico no Psicodiagnóstico Interventivo, este estudo visou averiguar a existência de associações entre as características de personalidade de uma pequena amostra de crianças com tendência anti-social, conforme avaliadas pela Técnica de Rorschach, e os seus resultados terapêuticos. Diante da carência de pesquisas sistematizadas dessa natureza, a intenção deste trabalho é a de contribuir para a definição de uma estimativa mais segura dos alcances e limites desse método de intervenção.

A opção pelo atendimento de crianças com comportamentos anti-sociais ocorreu em razão de que eles apresentam alta e crescente prevalência em nossa sociedade (A.P.A., 1994/1995; Rey, 1993; Webster-Stratton, 1993), além de acarretarem sérias conseqüências ao cumprir sua trilha evolutiva (Webster-Stratton, 1993). Os bons resultados obtidos por Winnicott (1971/1984) nas Consultas Terapêuticas com esses pacientes, a despeito do prognóstico sombrio que lhes é geralmente atribuído (Rey, 1993; Thomsen, 1996), completaram as razões da escolha. Maiores detalhes dessa patologia são expostos a seguir.

\section{A tendência anti-social}

\section{Aspectos psicopatológicos}

Na psiquiatria descritiva os sintomas referentes à tendência anti-social são agrupados na categoria de Transtorno de Conduta (CD) ou Transtorno Desafiador Opositivo (ODD) e incluem, segundo a
CID-10 (O.M.S., 1992/1993), comportamentos como níveis excessivos de brigas ou intimidações, crueldade com animais e com os pares, destruição de propriedade, piromania, roubo, mentiras, fugir de casa, ataques de birras freqüentes, desobediência grave e contínua. Segundo essa classificação, para adquirir significação diagnóstica é suficiente a presença de qualquer um desses comportamentos, desde que marcante, por um período mínimo de 6 meses.

O DSM-IV (A.P.A., 1994/1995) descreve os indivíduos com essas patologias como pouco empáticos ou preocupados com os sentimentos, desejos e bem-estar dos outros. Podem não apresentar sentimentos de culpa e remorso, que aprendem a simular para evitar punições. A auto-estima é baixa e há reduzida tolerância à frustração; ocorrem acessos de raiva, irritabilidade e imprudência, ocasionando um número alto de acidentes.

Uma diferença entre o DSM-IV e a CID-10 é que o primeiro concebe o Transtorno Desafiador de Oposição como uma categoria à parte do Distúrbio de Conduta, caracterizada pela presença de atitude hostil, desobediente e negativista para com as autoridades e comportamentos como perder a paciência, discutir, ser rancoroso e vingativo, importunar deliberadamente os outros e responsabilizá-los pelos próprios erros e má conduta. A despeito disso, a literatura científica é bastante controversa quanto a validade de distinguir os dois quadros, devido a sua alta comorbidade que oscila entre 84 e $96 \%$ segundo Hinshaw, Lahey e Art (conforme citados por Flanagan \& Flanagan, 1998) ou entre 77 e 84\% de acordo com Rey (1993).

Webster-Stratton (1993) considera o ODD como uma forma branda do CD, mas passível de agravamento, na medida em que percorre uma trilha evolutiva. Esta se iniciaria com a emergência do ODD nos anos pré-escolares, progredindo até os comportamentos dos Transtornos de Conduta na infância, e finalmente para os sintomas mais sérios da adolescência como a violência interpessoal e as violações de propriedade. Contudo, essa continuidade genética nem sempre existe, pois depende de fatores como a data de início dos comportamentos próprios ao ODD, os contextos em que eles surgem, sua freqüência, intensidade, cronicidade e diversidade, bem como das características familiares. 


\section{Valéria Barbieri}

Rey (1993) defende que o ODD e o CD são categorias distintas, argumentando que a análise fatorial apontou a existência de duas classes de comportamentos disruptivos, uma consistindo em condutas relativas ao primeiro quadro (agressão branda, brigas e intimidações) e a outra ao segundo (roubo, absenteísmo e fugas). Além disso, haveria diferenças no padrão evolutivo das patologias. Contudo, ao analisar pesquisas sobre a precisão diagnóstica do ODD, encontrou correlações bastante baixas, indicando pouca estabilidade dos sintomas que o definem.

Portanto, há poucos elementos que indiquem vantagem em compreender os dois quadros como distintos. Quanto à continuidade nem sempre presente entre eles, a explicação de Webster-Stratton (1993) sobre os fatores necessários para a sua ocorrência, é coerente e satisfatória. Desse modo, a denominação Transtorno de Conduta será aqui empregada como englobando o ODD, mantendo-se a distinção apenas nos casos em que a literatura forneça informações diferenciadas sobre cada uma das síndromes.

Segundo o DSM-IV (A.P.A., 1994/1995), a prevalência do CD tem aumentado nos últimos anos. Webster-Stratton (1993) afirma que nos Estados Unidos de 4 a $10 \%$ das crianças enquadram-se nos critérios dessa classificação. Rey (1993), coletando informações de 5 inquéritos epidemiológicos, expõe as faixas de prevalência de 1,7 a 9,9\% para o ODD e de 1,5 a 8,7\% para o CD. Tanto Rey como WebsterStratton afirmam que aproximadamente um terço das crianças com alguma dificuldade psicológica recebem o diagnóstico de Transtorno de Conduta (ODD incluído). A prevalência em crianças do sexo masculino é mais que o dobro do que nas do sexo feminino (Rey, 1993); o DSM-IV refere taxas de 6 a 16\% e de 2 a 9\% para meninos e meninas, respectivamente. Os sintomas também variam: nos meninos são mais comuns as brigas, furtos e vandalismo, enquanto nas meninas prevalecem as mentiras, cabular aulas, uso de drogas e prostituição.

Nos casos em que o CD cumpre a sua trilha evolutiva (Webster-Stratton, 1993), essa distinção sexual dos sintomas pode conduzir a diferentes diagnósticos na fase adulta. Svrakic e McCallum (1991) afirmam que alguns distúrbios neuróticos como a somatização histérica podem ocorrer junto com o comportamento anti-social, o que levaria os clínicos a diagnosticarem as mulheres predominantemente como 'histéricas' e os homens como 'anti-sociais'. Entretanto, afirmam que o CD não se vincula a nenhuma estrutura específica de personalidade, apesar de ser mais comumente sustentado pelas organizações borderlines.

Além da predisposição aos Transtornos de Personalidade Anti-Social (incluindo os associados ao uso de substâncias) e somatoformes, a presença do CD aumenta o risco para o surgimento dos distúrbios de humor e de ansiedade. Seus comportamentos característicos podem ainda conduzir à expulsão escolar, dificuldades de ajustamento ocupacional, problemas legais, contágio e difusão de doenças sexualmente transmissíveis, conseqüências de altíssimo custo social, principalmente quando se considera a prevalência do quadro.

Com referência à etiologia, Silberg e Cols. (1996), em estudo com gêmeos homo e dizigotos, concluíram que embora o fator genético seja importante na determinação dessa patologia, os efeitos das influências ambientais são fundamentais, especialmente para as meninas. Em acordo com essa conclusão, vários estudos demonstraram a existência de associações entre os Transtornos de Conduta infantis e práticas educativas inconsistentes (A.P.A., 1994/ 1995), permissividade ou restrição exageradas (Grünspun, 2000), discórdia conjugal (A.P.A., 1994/ 1995; Davies \& Windle, 1997; Webster-Stratton, 1993) e psicopatologia parental como distúrbios de personalidade anti-social, de humor, de déficit de atenção e hiperatividade, esquizofrenia, abuso de substâncias, ansiedade e depressão materna (A.P.A., 1994/1995; Frick e Cols. 1992; Nigg \& Hinshaw, 1998; Rey, 1993; Webster-Stratton, 1993). Experiências como falta de supervisão, institucionalização nos primeiros dias de vida e mudanças freqüentes dos responsáveis pela criança também estão associadas com o surgimento do CD (A.P.A., 1994/1995).

Coerentemente com essas verificações Grünspun (2000), ao referir-se à terapêutica da delinqüência, afirma que práticas como a psicoterapia, atendimento psicopedagógico ou mudança do ambiente da criança devem ser acompanhadas por intervenções com os pais, sendo a profilaxia da doença dirigida principalmente a eles. 
Rey (1993) comenta que, a despeito da variedade de práticas terapêuticas disponíveis para as crianças CD, é amplamente reconhecido que a sua resposta ao tratamento é pobre. Essa observação foi confirmada por Thomsem (1996) que verificou que a chance de uma criança inicialmente diagnosticada como CD ser readmitida em um hospital psiquiátrico após os 18 anos de idade era de $25 \%$. Dentre esses pacientes, aproximadamente 94\% foram diagnosticados posteriormente como apresentando abuso de álcool ou drogas.

\section{A compreensão psicanalítica}

Muitos dos aspectos descritivos dos Transtornos de Conduta podem ser melhor compreendidos e esclarecidos se examinados sob a ótica psicanalítica, por exemplo, sua etiologia, vínculo com organizações específicas de personalidade e maior prevalência no sexo masculino.

Alguns autores como Soifer (1992) e Kernberg (2000) sustentam que o predomínio de mecanismos psicopáticos se deve à existência de um superego de natureza débil, lacunar e deficitária. Contudo, as teorias mais tradicionais sobre a criminalidade, como as de Freud, Klein e Winnicott, rejeitam a idéia de que o superego do infrator seja mais frágil do que o do indivíduo normal, ou que esteja simplesmente ausente.

De acordo com Freud (1928/1976), o sentimento de culpa não apenas existe na mente do criminoso, como é anterior ao ato anti-social. O crime aconteceria em função de uma culpa inconsciente e seria usado para racionalizá-la. A psicodinâmica do criminoso remeteria ao Complexo de Édipo, especificamente ao processo de formação do superego no menino, tal como vivido por uma personalidade com forte disposição bissexual. Nessa ocasião, se o pai foi duro e cruel na realidade, o superego herdará dele esses atributos tornando-se sádico, enquanto o ego se converte em masoquista. Assim, este último desenvolve uma intensa necessidade de punição (castração), permitindo dessa maneira realizar a atitude passivo-feminina para com o pai. A necessidade masoquista do ego pode ser satisfeita por um castigo aplicado por um agente externo ou pelo próprio superego. Nesse sentido, Freud afirma que as crises histéricas constituem uma punição auto-infligida pelo desejo da morte de um pai odiado, em um processo de identificação com o objeto atacado. Esse pressuposto permite compreender a relação entre os transtornos anti-sociais e histéricos apontada por Svrakic e McCallum (1991), como centrada na distinção entre as principais formas de castigo, incluindo ou não a projeção do superego em um agente externo. As divergências entre meninos e meninas na maneira de experimentar a ansiedade de castração e entre as práticas educativas que lhes são dirigidas, explicariam suas diferenças de prevalência dos transtornos histéricos e anti-sociais.

Embora Freud considere a intensidade da disposição bissexual como o principal fator na etiologia do comportamento criminoso e atribua uma importância secundária à severidade e rigidez paterna, afirma que as reações edípicas dessa natureza podem desaparecer se não forem sustentadas pela realidade externa.

Klein (1927/1981) também aponta o Complexo de Édipo como ponto estratégico na etiologia da conduta criminosa, mas refere-se ao precoce. Ela aceita a dinâmica descrita por Freud, mas com duas diferenças: a coexistência entre fantasias genitais e pré-genitais (especialmente as sádico-orais e sádicoanais) e a presença, nesse momento, de um superego primitivo. As fantasias em relação ao casal parental (sujá-lo com fezes, arrancar com dentadas, cozinhar e comer o pênis do pai, apropriar-se e destruir os conteúdos do corpo da mãe) e ao coito (morder, arranhar e cortar) são empregadas para a formação do superego, e a criança acredita que os pais farão a ela o mesmo que ela quer fazer a eles. A angústia decorrente dessas fantasias obriga o ego a aplicar um poderoso recalque a toda a situação, que permanece ativa na mente inconsciente. A intensidade dessa defesa compromete a capacidade simbólica da criança, impedindo-a de brincar e obstruindo importantes canais para a sublimação; com isso a atuação passa a ser o único meio para expressar o desejo de castigo. Esse bloqueio da capacidade simbólica, a existência de um superego primitivo que funciona em dois níveis (um deles vinculado ao estágio genuinamente alcançado e o outro aos atos efetivamente realizados) e a presença de experiências reais que sustentem o seu caráter opressor, seriam atributos da criança anti-social. $\mathrm{O}$ valor imputado por Klein às experi- 


\section{Valéria Barbieri}

ências reais vai ao encontro das hipóteses de Freud (1928/1976) e Grünspun (2000) sobre a severidade e restrições exageradas do meio familiar como um dos fatores etiológicos dos transtornos anti-sociais. Não obstante, ela defende que não é a austeridade do superego o que distingue a criança anti-social, mas o seu funcionamento distinto. O superego do delinqüente conserva uma parte das tendências proibidas para se livrar de outras mais condenáveis, vinculadas ao Complexo de Édipo. Assim, cada vez que a criança pratica um delito, está buscando escapar da situação edípica. O castigo real, mesmo severo, é confortador se comparado aos ataques assassinos dos pais que ela fantasia.

Sobre as possibilidades de tratamento, Klein é bastante otimista, argumentando que se não há deficiência no superego mas apenas uma evolução diferente, a análise poderia modificar o comportamento criminoso do mesmo modo como remove as neuroses. Em 1934, ela afirma categoricamente a possibilidade de curar crianças anti-sociais por meio da análise.

Distintamente de Freud, Klein, Soifer e Kernberg, Winnicott (1956/1999) postula que a tendência anti-social não está relacionada à ausência, deficiência ou a um tipo específico de funcionamento superegóico. Segundo ele, a origem desse transtorno repousaria em um ‘complexo de privação’ ou falha do ambiente em oferecer à criança certas características essenciais da vida familiar. De acordo com sua teoria, após um período em que o meio atendeu às necessidades do bebê, ocorreu a perda de uma experiência boa com um objeto, que se manteve por um tempo maior do que a criança pudesse recordá-la, gerando quebra na continuidade de existência. Essa privação deve ter acontecido quando a criança já compreende que a causa do desastre é externa, e no momento em que realizava a fusão das raízes libidinais e agressivas do id (motilidade), o que responde pelas duas vertentes da tendência anti-social: furto e agressividade. No roubo a criança busca alguma coisa em algum lugar (a experiência perdida) e, não a encontrando, procura-a em outro (aquisição do objeto concreto). Já na destrutividade, a busca é por uma estabilidade ambiental confiável que tolere a tensão originada do comportamento impulsivo e, assim, permita à criança mover-se e exercitar-se mais livremente.
A despeito das condições evolutivas necessárias ao desenvolvimento da tendência anti-social, Winnicott (1956/1999) reitera que ela não é um diagnóstico em si, e pode ser encontrada tanto em um indivíduo normal, como em um neurótico ou psicótico. Quanto à conduta terapêutica, ele sustenta que o seu tratamento não é a psicanálise mas a provisão de cuidados estáveis por parte do ambiente, que deve dar apoio ao ego e promover oportunidades para a sua integração. Dessa maneira as chances de sucesso terapêutico dependeriam da qualidade do meio em que a criança vive.

A comparação entre os referenciais descritivo e psicanalítico sobre a tendência anti-social mostra que eles apresentam mais pontos de encontro do que divergências. Há certo acordo quanto ao ambiente familiar como fator etiológico e à dificuldade em vincular o quadro a uma organização específica de personalidade. Com relação à eficácia terapêutica, a abordagem psicanalítica é mais otimista. Enfim, se as hipóteses psicanalíticas nem sempre caminham harmonicamente com os estudos descritivos, ao menos fornecem-lhes uma compreensão mais profunda e enriquecedora.

Diante do preocupante alastramento da tendência anti-social, de suas graves conseqüências pessoais e sociais, e das controvérsias em torno do prognóstico (desanimador entre os estudos descritivos e otimista entre os psicanalíticos), este trabalho investigou as contribuições que o Psicodiagnóstico Interventivo poderia oferecer ao seu tratamento. Assim, por meio da aplicação individual do método a um pequeno grupo de crianças com esse quadro, averiguou-se a existência de associações entre seus resultados terapêuticos e características de personalidade indicadas por um teste psicológico, buscando definir mais claramente suas indicações e contra-indicações. $\mathrm{O}$ instrumento escolhido para essa avaliação foi a Técnica de Rorschach, devido à sua refinada sensibilidade clínica e suas comprovadas validade e precisão (Anzieu, 1961/1988), que permitem alcançar conteúdos muito profundos e significativos da personalidade preservando, ao mesmo tempo, o rigor científico. 


\section{Método}

\section{Sujeitos}

Oito crianças (seis meninos e duas meninas), entre 5 e 10 anos de idade, de nível sócio-econômico médio ou baixo, encaminhadas para atendimento psicológico devido a queixas relativas à tendência antisocial. Foram excluídas da amostra crianças vitimizadas, procedentes de lares desfeitos ou cujos genitores apresentassem graves comprometimentos psiquiátricos, devido à associação entre os resultados do método e a qualidade do meio familiar (Ancona-Lopez \& Cols., 1995; Winnicott, 1971/ 1984). Todos os pais assinaram um termo de consentimento livre e esclarecido, autorizando a sua participação e a do filho na pesquisa.

\section{Material}

No atendimento de cada sujeito foram utilizadas entrevistas de anamnese, a Técnica de Rorschach, duas sessões lúdicas, entrevista familiar diagnóstica, Bateria Gráfica de Hammer e Teste de Apercepção Infantil (CAT) forma animal, além de entrevistas devolutivas e de follow-up com os pais.

\section{Procedimento}

Foi feito um estudo de caso de cada criança, cuja primeira parte consistiu na realização de um diagnóstico clássico por meio de entrevistas de anamnese e aplicação da Técnica de Rorschach, que foi cotado de acordo com o sistema francês representado por Traubenberg (1970/1998) e avaliado segundo as normas brasileiras estabelecidas por Jacquemin (1975). A interpretação do teste foi realizada em termos das funções egóicas de Produção, Ritmo, Pensamento, Teste do Real, Controle dos Impulsos, Mecanismos de Defesa e Relacionamentos Interpessoais (além da Estrutura de Personalidade), definidas a partir de agrupamentos de índices do psicograma conforme propostos por Loureiro e Romaro (1985), mais significativas para a compreensão integrada da personalidade do que informações procedentes de indicadores isolados. Cada função foi classificada em termos de sua integridade ou com- prometimento em grau leve, moderado ou severo, independente da estrutura de personalidade subjacente, ou seja, crianças neuróticas poderiam apresentar prejuízos tão graves quanto as psicóticas.

Finalizada essa etapa, era iniciado o Psicodiagnóstico Interventivo propriamente dito, empregando-se sessões lúdicas, entrevista familiar diagnóstica, aplicação da Bateria Hammer e do CAT, sempre incluindo intervenções do examinador. A aplicação da Bateria Hammer foi dividida em duas sessões, a primeira visando a coleta tradicional do material, enquanto na segunda ele era discutido com a criança, sendo solicitadas associações e realizadas interpretações. Esse mesmo procedimento foi seguido na aplicação do CAT. Após esse processo havia a convocação dos pais para a entrevista devolutiva, seguida de orientações, e a criança era liberada, com a psicóloga colocando-se à disposição da família caso houvesse necessidade de retomar o atendimento. Todas as crianças foram atendidas pela mesma profissional e responderam às mesmas técnicas na ordem citada, à exceção de um caso (Leonardo) em que se incluiu uma avaliação intelectual (mediante o WISC) devido a suspeitas de comprometimentos cognitivos, que não se confirmaram. O período de follow-up variou entre 3 e 8 meses, e foi realizado por meio de entrevistas com os pais ou contato telefônico.

\section{Análise dos resultados}

Os dados foram analisados de maneira descritiva, comparando-se a estrutura de personalidade e o grau de comprometimento das funções egóicas de cada criança indicados na Técnica de Rorschach, com o sucesso ou fracasso terapêutico do método, de acordo com o relato dos pais no follow-up.

\section{Resultados e Discussão}

\section{Breve descrição dos casos}

1. Beatrice $e^{3}$ : menina de 10 anos de idade, nível sócio-econômico médio, residia com o pai, a madrasta e um irmão de 13 anos. A mãe biológica faleceu quando ela tinha 4 anos. Foi encami-

\footnotetext{
${ }^{3}$ Os nomes dos sujeitos foram alterados para fins de preservação de sua privacidade.
} 


\section{Valéria Barbieri}

nhada por uma neurologista devido a furtos de dinheiro dos familiares, que deixaram de acontecer após o término do atendimento. O followup se estendeu por 6 meses.

2. Leonardo: menino de 10 anos, nível sócio econômico baixo, residia com o pai, a mãe e um irmão de 22 anos. Foi encaminhado pela diretora da escola devido a agitação, brigas com os colegas e insubordinação aos professores, comportamentos que não aconteciam em casa. $\mathrm{O}$ período de seguimento do caso foi de 3 meses, com a mãe relatando melhora acentuada dos sintomas, não tendo mais recebido reclamações da escola.

3. Tiago: menino de 8 anos, nível sócio-econômico baixo, residia com os pais, um irmão de 5 anos e uma irmãzinha de 3 . Foi encaminhado por uma orientadora educacional, amiga da família, que descreveu a ele e ao irmão como crianças más, agressivas e desobedientes. Os pais, no entanto, o apresentaram como um menino doce, tranqüilo e inteligente, e se preocupavam com o fato de ele não expressar seus sentimentos, apesar de brigar muito com o irmão. Ao final do trabalho relataram melhoras, afirmando que o filho estava mais ‘chato', exigente e capaz de expressar o que desejava. O follow-up se estendeu por 8 meses.

4. Rafael: menino de 5 anos, irmão de Tiago. Foi descrito pelos pais como desobediente, teimoso, rebelde e muito ciumento em relação à irmã. Um ano antes do atendimento maltratava seu cachorro e arrancava as folhas de uma planta, da qual agora cuidava. Após o término da intervenção, embora os pais relatassem sua melhora significativa, ele solicitou continuidade do atendimento. Foi iniciada ludoterapia que durou apenas 3 meses, porque a família se mudou para outra cidade.

5. Paulinho: menino de 8 anos, nível sócio-econômico médio, residia com os pais, uma irmã de 13 anos e outra de 1 mês. Foi encaminhado pela diretora da escola devido a brigas com os cole- gas, mentiras, uma fuga e um episódio de furto. Foi descrito pelos pais como um menino que irritava e atormentava os demais, embora cuidasse de crianças pequenas. No decorrer do atendimento, o pai demonstrou que não concordava com as queixas, argumentando que havia exagero quanto a elas por parte da mãe e da escola. No final do trabalho o casal relatou melhora moderada dos sintomas mas, 5 meses depois, a mãe contatou a psicóloga dizendo que eles haviam retornado e solicitando continuidade do tratamento. Paulinho foi atendido por mais 3 anos pela psicóloga, tendo posteriormente abandonado a ludoterapia em razão de conflitos entre os pais sobre quem deveria trazê-lo às sessões. Há um mês a mãe tentou retomar o atendimento do filho, mas diante da impossibilidade da psicóloga em realizá-lo, ele foi encaminhado a um profissional conveniado ao plano de saúde da família.

6. Daniel: menino de 8 anos, filho único, adotado com 1 dia de vida. Foi encaminhado pela diretora da escola por ser desobediente e agitado, tendo já recebido um diagnóstico de hiperatividade. Os pais contaram que ele destruía brinquedos e os rasgava com estilete, tinha alucinações visuais e auditivas. Recusava a alimentação, a menos que a mãe lhe desse a comida na boca. Também não aceitava dormir no próprio quarto, que passou a ser ocupado pelo pai, enquanto ele dormia com a mãe. Ao longo do tratamento, apresentou melhoras e passou a dormir sozinho em seu quarto. Contudo, na última sessão estava angustiado e exigiu a presença da mãe na sala de atendimento. A psicóloga ofereceu-se para iniciar tratamento ludoterápico, mas ele não o desejou. O follow-up se estendeu por 4 meses, havendo retorno dos sintomas.

7. Michael: menino de 10 anos de idade, filho único, nível sócio-econômico médio. Foi encaminhado pela diretora da escola por desatenção, recusa a cumprir as atividades acadêmicas e agressividade para com os colegas, queixas compartilhadas pelos pais e pela própria criança. $\mathrm{O}$ casal apresentava sérios conflitos conjugais, ten- 
do sido cogitada a possibilidade de separação. $\mathrm{O}$ seguimento do caso estendeu-se por 3 meses, sem melhora. Embora a psicóloga se dispusesse a prosseguir o atendimento do menino, não foi mais procurada pela família.

8. Alice: menina de 9 anos, baixo nível sócio-econômico, morava com os pais, um irmão de 20 anos e duas irmãs de 15 e 12 anos. Foi encaminhada pela diretora da escola porque não copiava a lição, brigava com os colegas, era desobediente, distraída e tinha dificuldades de memorização. Ela compareceu somente a duas sessões, sendo que na primeira preferiu brincar com o próprio corpo e roupas, ignorando a psicóloga (o que inviabilizou a aplicação da Técnica de Rorschach). Na segunda vez exigiu que a irmã permanecesse na sala de atendimento e, mesmo assim, não quis continuar o trabalho.

Portanto, dos 8 casos atendidos, 7 foram concluídos, que forneceram a base para a análise dos dados.

Em termos do primeiro objetivo da avaliação psicológica interventiva, de implementar a compreensão diagnóstica, incluindo a exploração das reações do paciente às interpretações e sua capacidade de insight (Friedenthal, 1976; Santiago, 1995), todos os casos poderiam ser considerados como bem sucedidos. Informações relativas à ação e flexibilidade dos mecanismos de defesa, às resistências, à permeabilidade entre consciente e inconsciente e à cooperação do paciente em uma psicoterapia posterior surgem mais claramente do que no procedimento tradicional. Além disso, o uso de assinalamentos e interpretações ao longo do processo permite testar as hipóteses diagnósticas à medida em que elas surgem, conduzindo a uma avaliação final mais segura e fidedigna. Como exemplo, no caso de Rafael, a interpretação de que os «negócios coloridos» que ele desenhava (uma espécie de arco-íris com soldados no final de cada cor pintada) eram um problema, porque por mais que fossem vigiados, eles conseguiam escapar, foi avidamente aceita pelo menino, demonstrando não apenas sua capacidade de insight, mas também confirmando a suposição da psicóloga sobre a existência de dificuldades de integração dos afetos na personalidade, ainda que não acentuadas. Dessa maneira, o Psicodiagnóstico Interventivo efetivamente enriquece os procedimentos clássicos de avaliação e incrementa sua eficácia e confiabilidade, resultando em encaminhamentos mais compatíveis com as necessidades e recursos do paciente.

Quanto aos efeitos terapêuticos do método, embora ele tenha proporcionado a todas as crianças maior contato com sua realidade interna, mesmo àquelas que não desejaram prosseguir o atendimento (Barbieri, 2002), quando sua eficácia foi estimada por meio da melhora dos sintomas, verificou-se diferenças importantes entre os sujeitos.

De acordo com esse critério, os casos de Beatrice, Leonardo e Tiago enquadraram-se na categoria de «sucessos terapêuticos», enquanto Daniel e Michael foram definidos como «fracassos». Rafael e Paulinho também foram classificados como sucessos apesar da necessidade de atendimento posterior, em razão das assertivas de Winnicott (1971/1984) e Ody (1993) de que a função da Consulta Terapêutica não é apenas a de evitar indicações intempestivas de análise, mas também a de melhor prepará-las. Assim, se para Winnicott e Ody a pretensão desse método não é substituir a psicoterapia quando ela é necessária mas quando não o é, também não seria falha do Psicodiagnóstico Interventivo se ele conduzir a outro tipo de tratamento.

A inclusão de Rafael e Paulinho na categoria sucessos não deve, contudo, obscurecer duas diferenças entre os casos: no primeiro houve demanda da própria criança para prosseguir o atendimento e as melhoras alcançadas foram mantidas, enquanto no segundo houve resistência inicial à ludoterapia e a atenuação dos sintomas foi provisória. Assim, seria mais correto considerar Paulinho como um caso apenas parcialmente bem sucedido. Portanto, elegendose o critério de melhora dos sintomas como parâmetro da análise dos dados desta pesquisa, a aplicação do Psicodiagnóstico Interventivo conduziu a 5 sucessos e 2 malogros terapêuticos.

A contraposição desses resultados com as características e funções egóicas das crianças, conforme avaliadas pela Técnica de Rorschach, indicou que a Estrutura de Personalidade, a acuidade do Controle Pulsional (incluindo o Funcionamento Defensivo) e a qualidade dos Relacionamentos Pessoais 


\section{Valéria Barbieri}

(abrangendo o caráter parcial ou total dos vínculos) discriminaram entre os casos bem e mal sucedidos, como pode ser visto na tabela abaixo.

Tabela 1: Características das crianças atendidas que discriminaram entre os sucessos e os fracassos no Psicodiagnóstico Interventivo.

\begin{tabular}{|lllll|}
\hline Criança & $\begin{array}{c}\text { Resultado } \\
\text { Terapêutico }\end{array}$ & $\begin{array}{l}\text { Estrutura de } \\
\text { Personalidade }\end{array}$ & $\begin{array}{c}\text { Controle Pulsional } \\
\text { (Comprometimento) }\end{array}$ & $\begin{array}{c}\text { Relacionamentos } \\
\text { Pessoais } \\
\text { (Comprometimento) }\end{array}$ \\
\hline $\begin{array}{l}\text { Beatrice } \\
\text { Leonardo }\end{array}$ & Sucesso & Neurótica & Preservado & Preservados \\
Tiago & Sucesso & Neurótica & Moderado & Moderado \\
Rafael & Sucesso & Neurótica & Preservado & Leve \\
Paulinho & Sucesso & Neurótica & Leve & Moderado \\
Daniel & Sucesso & Neurótica & Moderado & Moderado \\
Michael & Fracasso & Psicótica & Severo & Severo \\
\hline
\end{tabular}

Por sua vez, a idade do sujeito, a Produção, o Ritmo, as condições do Pensamento e do Teste do Real não se associaram aos resultados terapêuticos, como demonstrado na tabela 2 .

Tabela 2: Funções egóicas das crianças que não se associaram aos resultados no Psicodiagnóstico Interventivo.

\begin{tabular}{|lccclcc|}
\hline Criança & $\begin{array}{c}\text { Resultado } \\
\text { Terapêutico }\end{array}$ & $\begin{array}{c}\text { Idade } \\
\text { (anos) }\end{array}$ & Produção & Ritmo & $\begin{array}{c}\text { Qualidade do } \\
\text { Pensamento }\end{array}$ & $\begin{array}{c}\text { Teste do Real } \\
\text { (Comprometimento) }\end{array}$ \\
\hline Beatrice & Sucesso & 10 & Baixa & Lento & Inibido & Leve \\
Leonardo & Sucesso & 10 & Baixa & Lento & Inibido & Moderado \\
Tiago & Sucesso & 8 & Baixa & Rápido & Preservado & Leve \\
Rafael & Sucesso & 5 & Baixa & Médio & Inibido & Moderado \\
Paulinho & Sucesso & 8 & Alta & Lento & Inibido & Leve \\
Daniel & Fracasso & 8 & Alta & Rápido & Inibido & Moderado \\
Michael & Fracasso & 10 & Baixa & Lento & Inibido & Severo \\
\hline
\end{tabular}

Com relação à estrutura de personalidade, a tabela 1 mostra que todas as crianças com organização neurótica obtiveram êxito total ou parcial no trabalho, ao passo que as psicóticas constituíram-se nos malogros. Pela mesma tabela verifica-se que o nível evolutivo do controle pulsional dos sujeitos bem sucedidos foi compatível com a idade (Beatrice e Tiago) ou, quando houve indicação de imaturidade, seu grau foi leve (Rafael) ou moderado (Leonardo e Paulinho), enquanto nos casos de insucesso o prejuízo foi grave. Acompanhando essa tendência, a análise dos Relacionamentos Pessoais mostrou que nos casos de sucesso eles se encontravam preservados (Beatrice) ou mostravam comprometimento leve (Tiago) ou moderado (Leonardo, Rafael e Paulinho), ao contrário das situações de fracasso, em que a intensidade do prejuízo foi severa. Não obstante, nenhuma criança apresentou relações de objeto predominantemente parciais, mesmo as psicóticas, cujos vínculos oscilavam entre parciais e totais.

Esses resultados, particularmente os referentes à organização da personalidade, vão ao encontro das conclusões de Ody (1993) e Brafman (1997 e 1999) sobre os alcances da Consulta Terapêutica. Nesse sentido, Ody afirma que se a qualidade estrutural da criança estiver presente, as resoluções sintomáticas que acontecem durante essa intervenção tornam prescindível uma psicoterapia individual. Por 
outro lado, Winnicott (1971/1984) afirma que é possível realizar Consultas Terapêuticas eficazes mesmo com crianças muito doentes, o que ilustra mediante o relato de sua utilização em vários casos de psicose infantil.

A desavença entre os resultados de Winnicott e os desta pesquisa é passível de compreensão, pelo menos em parte, quando se considera as diferenças entre as técnicas utilizadas nos dois métodos, pois os testes projetivos, mais estruturados que o Jogo dos Rabiscos, podem forçar a emersão de material inconsciente de modo abrupto e nem sempre condizente com o ritmo e as capacidades da criança. Assim, para fazer frente à quantidade e natureza desse material, seria necessário dispor de uma personalidade razoavelmente integrada e capaz de abarcá-lo sem correr o risco de desorganizar-se. Essa hipótese, contudo, não é definitiva, tanto em função do pequeno número de crianças psicóticas da amostra, quanto da existência de outras suposições igualmente viáveis de explicar os fracassos. Nesse sentido, Daniel estava preso em um vínculo simbiótico com a mãe, e no caso Michael havia presença de características paranóides no menino e de conflitos conjugais entre os pais, fatores de risco dos Transtornos de Conduta e empecilhos à boa evolução do caso (Davies \& Windle, 1997; WebsterStratton, 1993; Winnicott, 1956/1999). Portanto, não é possível afirmar com segurança se a organização psicótica é, em si mesma, obstáculo para o sucesso do Psicodiagnóstico Interventivo, ou se isso ocorre apenas quando está associada a outros elementos prognósticos negativos.

Os resultados referentes ao Controle Pulsional dos casos bem sucedidos revelam capacidade de integração das pulsões no self. Em Beatrice, Tiago e Rafael essa habilidade, que permite usufruir mais livremente das pulsões, é confirmada pela ressonância afetiva introversiva das duas primeiras crianças e extratensiva da última. Em Leonardo, contudo, o controle restritivo-inibidor dos afetos, acompanhado pela ressonância atual e latente coartativas, sugere maior rigidez, que o impede de vibrar afetivamente com a realidade ou de se deixar levar pela imaginação, aspectos condizentes com o maior uso da repressão. Discutindo sobre a psicoterapia de crianças com dificuldades semelhantes, Ody (1993) sustenta que nesses casos as intervenções do analista são pou- co mobilizadoras e somente o trabalho de Consulta Terapêutica é possível, com ou sem tratamento complementar. Essa observação, todavia, é mais útil como critério para a contra-indicação dessas crianças à análise do que para sua indicação à Consulta, deixando ainda distante uma compreensão satisfatória da questão. De qualquer maneira, os resultados aqui obtidos indicaram ser possível a uma criança com certa rigidez defensiva se beneficiar com o Psicodiagnóstico Interventivo.

Quanto aos Relacionamentos Interpessoais, dentre os sujeitos bem sucedidos somente Paulinho não apresentava predomínio do vínculo com o objeto integral, devido ao emprego de defesas obsessivas ( $\uparrow \mathrm{Dd}$ ) que levavam sua concepção a oscilar entre total e parcial. A natureza dos comprometimentos leves e moderados nessa função referiram-se à dificuldades de empatia (Leonardo e Rafael) ou à percepção fantasiosa do outro (Tiago e Paulinho), mas não a ponto de ocasionar sérias distorções perceptivas, como indicado nos protocolos de Daniel e Michael.

Abordando a capacidade de se vincular afetivamente a partir de indicadores da Técnica de Rorschach, Halpern (1953) sinaliza que é difícil alcançar o contato com uma criança que fornece somente uma resposta cor, pois ela teria se afastado do ambiente, sendo minimamente responsiva às suas pressões emocionais. Contudo, dentre os sujeitos desta pesquisa a emissão de respostas $F C$ e $C F$ não se associou ao resultado terapêutico, havendo casos de fracasso em que o protocolo exibia maior quantidade delas do que em alguns sucessos. Portanto, a avaliação integrada dos índices da técnica referentes aos Relacionamentos Interpessoais foi mais significativa para o prognóstico do Psicodiagnóstico Interventivo, do que a consideração isolada deles.

Em suma, de acordo com a Técnica de Rorschach, uma criança que apresente tendência antisocial no contexto de uma organização neurótica de personalidade, na qual seja viável certo grau de integração das pulsões no self, que não empregue a repressão de modo excessivo, e tenha capacidade estrutural para vincular-se afetivamente nos termos de uma relação de objeto total, tem boas possibilidades de se beneficiar de um trabalho como o Psicodiagnóstico Interventivo. 


\section{Valéria Barbieri}

Quanto às demais funções egóicas avaliadas, é de especial interesse o fato de a qualidade do pensamento - preservada ou inibida por problemática afetiva - não ter se associado aos resultados terapêuticos (tabela 2), pois obriga a refletir sobre o valor do insight nessa prática clínica. A análise das respostas de movimento humano (K), indicadoras da criatividade, maturidade e consciência da vida interior, mostrou que sua freqüência foi elevada nos protocolos das crianças classificadas como sucesso terapêutico total, com exceção de Leonardo. O caso de sucesso parcial (Paulinho) e um dos insucessos (Daniel) apresentaram poucas respostas desse tipo. Quanto a Michael, embora ele exibisse uma porcentagem maior de K (10\%) em relação à norma para sua idade e sexo $(7,1 \%)$, isso ocorreu em função de uma única resposta dessa natureza em um protocolo completo de 10, não se tratando, portanto, de aumento genuíno. Essa tendência à associação entre o número de $\mathrm{K}$ e os resultados terapêuticos confirma em parte a acepção de Halpern (1953) sobre o prognóstico negativo de crianças com pouca capacidade de internalizar seus sentimentos. Segundo ela, esse tipo de paciente costuma se relacionar sob bases de muita exigência e dependência dos demais, sendo difícil transportá-los para um nível mais auto-suficiente. Portanto, os resultados desta pesquisa revelam que a maturidade do sujeito em relação à sua vida interior, passível de conduzi-lo ao insight, desempenha um papel importante na obtenção da melhora no Psicodiagnóstico Interventivo, mas não é condição sine qua non para ela.

Em relação ao Teste do Real, embora não tenha se vinculado aos resultados terapêuticos, sua importância para o Psicodiagnóstico Interventivo precisa ser investigada em amostras maiores, pois o contato acurado com a realidade permitiria à criança perceber mudanças nas atitudes parentais (também decorrentes dos efeitos do método), estabelecendo um círculo benigno de influência mútua entre pais e filhos.

O 'perfil' dos casos bem sucedidos confirma as conclusões de Anzieu (1961/1988) de que, se um protocolo do Rorschach exibe uma estrutura de personalidade intacta, à exceção de um ou dois pontos, isso significa que o sintoma é temporário ou parcial. Da mesma maneira Halpern (1953) sustenta que se a personalidade retratada pelos testes é relativamente estável e bem integrada, o sintoma é uma manifestação passiva e não indicação de transtorno profundo subjacente.

Embora as afirmações de Halpern e Anzieu sugiram que as melhoras dos sujeitos desta pesquisa foram 'espontâneas', Winnicott (1971/1984) assevera que se os furtos de uma criança cessam após a Consulta Terapêutica, isso significa que o trabalho realizado foi efetivo. Essa verificação, aliada à natureza não situacional dos sintomas das crianças, diminui a chance de ter sido espontânea a interrupção deles logo após a aplicação do método. De fato, apesar de ser viável ao Psicodiagnóstico Interventivo auxiliar sujeitos com comprometimentos situacionais, seu alcance parece ser bem maior, incluindo patologias que estão em processo de organização, mas não totalmente sistematizadas.

\section{Conclusão}

A análise dos dados do psicograma da Técnica de Rorschach revelou que crianças com organização neurótica de personalidade, que apresentavam no máximo comprometimentos moderados nos Relacionamentos Interpessoais e no Controle Pulsional (incluindo o Funcionamento Defensivo) foram mais propensas a se beneficiar com o Psicodiagnóstico Interventivo.

A despeito desses resultados, a 'simplicidade' do caso não deve ser o único critério para a indicação da criança a essa forma de atendimento. Devido à importância do papel dos pais em intervenções dessa natureza (Ancona-Lopez \& Cols., 1995; Barbieri, 2002), é fundamental considerar também, mesmo em situações complexas, o efeito que o encaminhamento do filho a uma psicoterapia clássica e prolongada pode ter sobre a família. O sentimento de fracasso, passível de emergir nessa situação, pode comprometer a estabilidade ambiental que a criança necessita para ter um desenvolvimento saudável, e arruinar mesmo uma bem intencionada ludoterapia.

No mesmo sentido, os êxitos alcançados por Winnicott (1971/1984) na aplicação da Consulta Terapêutica a crianças seriamente comprometidas, faz com que os resultados desta pesquisa, embora relativamente seguros com relação às indicações ao 
Psicodiagnóstico Interventivo, sejam preliminares com referência às contra-indicações.

Portanto, embora a presente investigação preencha uma lacuna importante no conhecimento dos alcances e limites desse novo método de atendimento, é necessária a sua complementação por trabalhos que averiguem, e em amostras maiores, os seus efeitos sobre pacientes psicóticos, e que empreguem outros instrumentos para conferir a precisão dos indicadores prognósticos da Técnica de Rorschach.

\section{Referências Bibliográficas}

Aberastury, A. (1986). Psicanálise da criança. (A.L.L. Campos, Trad.) Porto Alegre: Artes Médicas. (Trabalho original publicado em 1979).

American Psychiatric Association - A.P.A. (1995). Manual diagnóstico e estatístico de transtornos mentais DSM-IV. (D. Batista, Trad.) Porto Alegre: Artes Médicas. (Trabalho original publicado em 1994).

Ancona-Lopez, M. \& Cols. (1995). Psicodiagnóstico: processo de intervenção. São Paulo: Cortez.

Anzieu, D. (1988). Os métodos projetivos. (M.L.E. Silva, Trad.) Rio de Janeiro: Campus (Trabalho original publicado em 1961).

Barbieri, V. (2002). A família e o psicodiagnóstico como recursos terapêuticos no tratamento dos transtornos de conduta infantis. Tese de Doutorado. Instituto de Psicologia da Universidade de São Paulo, São Paulo.

Bellak, L. (1974). The TAT, CAT and SAT in clinical use. New York: Grune \& Stratton.

Brafman, A.H. (1997). Winnicotts Therapeutic Consultation revisited. International Journal of Psycho-Analysis, 78, 773-787.

Brafman, A.H. (1999). Tirando partido das influências mútuas entre pais e filhos. Revista Brasileira de Psicanálise,33(2), 339-361.

Cunha, J.A. \& Cols. (2000). Psicodiagnóstico V. Porto Alegre: Artes Médicas.

Davies, P.T. \& Windle, M. (1997). Gender specific pathways between maternal depressive symptoms, family discord and adolescent adjustment. Developmental Psychology, 33 (4 ), 657-668.

Flanagan, J.S. \& Flanagan, R.S. (1998). Assessment and diagnosis of Conduct Disorder. Journal of Counseling and Development. Spring, 76, 189197.

Freud, S. (1976). Dostoievski e o parricídio. Em Edição Standar das Obras Completas de Sigmund Freud. (Trad. sob a direção geral de J., Salomão) (pp. 203-223). vol. XXI, Rio de Janeiro: Imago (Originalmente publicado em 1928).

Frick, P.J., Lahey, B.B., Loeber, R., Loeber, M.S., Christ, M.A. \& Hanson, K. (1992). Familial risk factors to Oppositional Defiant Disorder and Conduct Disorder: parental psychopathology and maternal parenting. Journal of Consulting and Clinical Psychology, 60(1), 49-55.

Friedenthal, H. (1976). Interrogatório, test de limites y señalamientos en el Test de Relaciones Objetales. Em R.F. Verthelyi (org.), El Test de Relaciones Objetales de H. Phillipson (pp. 6195). Buenos Aires: Nueva Vision.

Gomes, I.C. \& Bronstein, M.(2000). O psicodiagnóstico como forma terapêutica: o uso da hora lúdica num caso de obesidade infantil grave [Resumo]. Em Sociedade Brasileira de Rorschach e Outros Métodos Projetivos. Resumos e Programas (p.74). Porto Alegre: SBRO.

Grünspun, H. (2000). Distúrbios Psiquiátricos da Criança. São Paulo: Atheneu.

Halpern, F. (1953). A clinical approach to children's Rorschach. New York: Grune \& Stratton.

Jacquemin, A.A. (1975). O Teste de Rorschach em crianças brasileiras: pesquisa e atlas. São Paulo: Vetor.

Kernberg, P.L. (2000). L'enfant anti-social. Em C. Geissman \& D. Houzel (orgs.), L'enfant, ses parents et le psychanalyste (pp. 849-864). Paris: Bayard Éditions.

Klein, M. (1981). Tendências criminais em crianças 
166 Valéria Barbieri

normais. Em Contribuições à Psicanálise (M. Maillet, Trad.) (pp. 233-252). São Paulo: Mestre Jou (Originalmente publicado em 1927).

Klein, M. (1981). Sobre a criminalidade. Em Contribuições à Psicanálise. (M. Maillet, Trad.) (pp. 349-354). São Paulo: Mestre Jou (Originalmente publicado em 1934).

Loureiro, S.R. \& Romaro, R.A. (1985). A utilização das técnicas projetivas, Bateria de Grafismo de Hammer e Desiderativo como instrumentos de diagnóstico - estudo preliminar. Arquivos Brasileiros de Psicologia, 37 (3), 132-141.

Morgan, C. \& Murray, H.A. (1935). A method for investigating fantasies: the Thematic Apperception Test. Archives of Neurology and Psychiatry, 34, 289-306.

Nigg, J.T. \& Hinshaw, S.P. (1998). Parent personality and psychopathology associated with antisocial behaviors in childhood Attention-Deficit Hyperactivity Disorder. Journal of Child Psychology and Psychiatry, 39(2), 145-159.

Ody, M. (1993). La question de l'interpretation en consultation thérapeutique de l'enfant. Revue Française de Psychanalyse, 1, 147-156.

Ocampo, M.L.S., Arzeno, M.E.G. \& Piccolo, E.G. (1987). O processo psicodiagnóstico e as técnicas projetivas. (M. Felzenswalb, Trad.) São Paulo: Martins Fontes (Trabalho original publicado em 1979).

Organização Mundial de Saúde - O.M.S. (1993). Classificação dos Transtornos Mentais e de Comportamento da CID-10: descrições clínicas e diretrizes diagnósticas. (D. Caetano, Trad.) Porto Alegre: Artes Médicas (Trabalho original publicado em 1992).

Rey, J.M. (1993). Oppositional defiant disorder. American Journal of Psychiatry. 150(12), December, 1769-1778.

Santiago, M.D.E. (1995). Psicodiagnóstico: uma prática em crise ou uma prática na crise? Em M. Ancona-Lopez \& Cols. Psicodiagnóstico: processo de intervenção (pp. 9-25). São Paulo:

\section{Cortez.}

Shields, W. (1999). Hope and the inclination to be troublesome: Winnicott and the treatment of Character Disorder in Group Therapy. International Journal of Group Therapy. 50(1), 87-103.

Silberg, J., Meyer, J., Maes, H., Simonoff, E., Pickles, A., Rutter, M., Hewitt, J., Loeber, R. \& Eaves, L. (1996). Genetic and environmental influences on the covariation between Hyperactivity and Conduct Disturbance in juvenile twins. Journal of Children Psychology and Psuchiatry, 37( 7), 803-816.

Soifer, R. (1992). Psiquiatria infantil operativa: psicologia evolutiva e psicopatologia. (J.C.A. Abreu, Trad.) Porto Alegre: Artes Médicas. (Trabalho original publicado $s / d$ ).

Svrakic, D.M. \& McCallum, K. (1991). Antisocial behavior and personality disorders. American Journal of Psychotherapy,.XLV(2), April, 181197.

Thomsem, P.H. (1996). A 22-to-25-year follow-up study of former child psychiatric patients: a register based investigation of the course of psychiatric disorder and mortality in 546 Danish child psychiatric patients. Acta Psychiatrica Scandinavica, 94, 397-403.

Traubenberg, N.R. (1998). A prática do Rorschach. (A.J. Lelé, Trad.) São Paulo: Vetor. (Trabalho original publicado em 1970).

Trinca, W. (Org.) (1997). Formas de investigação clínica em Psicologia: Procedimento de Desenhos-Estórias e Procedimento de Desenhos de Família com Estórias. São Paulo: Vetor.

Webster-Stratton, C. (1993). Strategies for helping early school-aged children with Opposiitonal Defiant and Conduct Disorders: the importance of home-school partnerships. Journal of Child Psychology and Psychiatry, 22(3), 437-457.

Winnicott, D.W. (1984). Consultas Terapêuticas em Psiquiatria Infantil. (J.M.X. Cunha, Trad.) Rio 
de Janeiro: Imago (Originalmente publicado em 1971).

Winnicott, D.W. (1993). Pediatria e Psiquiatria. Em Textos selecionados: da Pediatria à Psicanálise. (J. Russo, Trad.). (pp. 287-311). Rio de Janeiro: Francisco Alves (Originalmente publicado em 1948).

Winnicott, D.W. (1999). A tendência anti-social. Em Privação e delinqüência. (A. Cabral, Trad.). (pp. 135-147). São Paulo: Martins Fontes (Originalmente publicado em 1956).

Este manuscrito refere-se à Tese de Doutorado de Valéria Barbieri, defendida no Instituto de Psicologia da Universidade de São Paulo (IPUSP), sob a orientação do Prof. Dr. André Jacquemin e da Profa. Dra. Zélia Maria Mendes Biasoli Alves. 